\title{
Extraction of low molecular weight acids from transformer liquids using water extraction technique
}

DOI:

10.1109/ICPADM.2018.8401218

\section{Document Version}

Accepted author manuscript

Link to publication record in Manchester Research Explorer

\section{Citation for published version (APA):}

Yan, Z. W., Matharage, S., Liu, Q., \& Wang, Z. (2018). Extraction of low molecular weight acids from transformer liquids using water extraction technique. In ICPADM 2018 - 12th International Conference on the Properties and Applications of Dielectric Materials (pp. 198-201). (Proceedings of the IEEE International Conference on Properties and Applications of Dielectric Materials; Vol. 2018-May). https://doi.org/10.1109/ICPADM.2018.8401218

\section{Published in:}

ICPADM 2018 - 12th International Conference on the Properties and Applications of Dielectric Materials

\section{Citing this paper}

Please note that where the full-text provided on Manchester Research Explorer is the Author Accepted Manuscript or Proof version this may differ from the final Published version. If citing, it is advised that you check and use the publisher's definitive version.

\section{General rights}

Copyright and moral rights for the publications made accessible in the Research Explorer are retained by the authors and/or other copyright owners and it is a condition of accessing publications that users recognise and abide by the legal requirements associated with these rights.

\section{Takedown policy}

If you believe that this document breaches copyright please refer to the University of Manchester's Takedown Procedures [http://man.ac.uk/04Y6Bo] or contact uml.scholarlycommunications@manchester.ac.uk providing relevant details, so we can investigate your claim.

\section{OPEN ACCESS}




\title{
Extraction of low molecular weight acids from transformer liquids using water extraction technique
}

\author{
Z. W. Yan, S.Y. Matharage, Q. Liu, and Z.D. Wang \\ The University of Manchester \\ Manchester M13 9PL \\ United Kingdom
}

\begin{abstract}
Acidity has been recognised to be an excellent marker of the transformer insulation system. In the recent decade, a subgroup of the acids, known as low molecular weight acids (LMA), have been identified to be the cause of acid catalysed degradation of the paper insulation. Due to the unavailability of a standard method, LMA in transformer oil is commonly measured through a water-extraction process where LMA is extracted into water prior to the titration. This contribution investigates the effects of some key parameters of the extraction process including stirring speed, stirring duration and the separation period. Experiments are conducted with two types of transformer liquids including a mineral oil and a synthetic ester. Results indicate that the best extraction efficiency for the transformer liquids can be reached at a stirring speed of $650 \mathrm{rpm}$. Furthermore, it is found that the LMA extraction is completed within 1 hour and 3 hours of stirring for the mineral oil and the synthetic ester, respectively. The mineral oil had higher LMA extracted in water than the synthetic ester in a wide range of initial acidity concentration. This is due to a residual amount of LMA remaining in the ester liquid irrespective of the initial acidity.
\end{abstract}

\section{INTRODUCTION}

Extensive studies on the UK transformer population have found that around 50\% of the transformers are reaching 50 years of operating time, which is beyond their design life [1]. To avoid failure of these expensive and important assets, information on their conditions are collected through chemical ageing markers in transformer liquid, which allows network operators to plan for timely maintenance and replacement.

A transformer's insulation system comprises of paper insulation immersed in insulating liquid (commonly mineral oil) to protect the windings from short-circuit failures. Paper insulation cannot be removed during operation unlike transformer insulating liquids and additionally its degradation mechanism is an irreversible reaction. As a consequence, a transformer's health condition is closely linked to the condition of the paper insulation.

Transformer insulation paper is mainly made from softwood Kraft pulp and its constituents are: cellulose, hemi-cellulose and lignin. Paper degradation occurs through oxidation, hydrolysis and pyrolysis where the insulation is exposed to chemical, physical or thermal stresses for long periods of time [2]. These reactions will lead to the production of different molecular by-products (such as $\mathrm{CO}, \mathrm{CO}_{2}$, furfural compounds and methanol), which can be used to monitor the condition of the paper insulation [3]. Degradation of transformer insulation initiates with the oxidation of transformer liquid and paper due to their lower activation energy and the abundance of oxygen at the initial stage of a transformer's operating life [4]. These reactions produce acids that dissociate to form hydronium ions. The generation of acidic by-products slowly suppresses the oxidation reactions and promotes hydrolysis leading to the production of more water and acids. The processes can thus be regarded as an acid catalysed autocatalytic reaction [4].

Acidic by-products are one of the core molecular groups involved in the molecular interactions during the lifetime of a transformer [4]. Not surprisingly, it is recognised as a prominent chemical marker for transformer liquid and a potential marker for paper insulation [4, 5]. Acids produced during the ageing process can be further categorized as low molecular weight acids (LMA) and high molecular weight acids (HMA), both of which are carboxylic acids [6]. The contribution of these different types of acids to the ageing process of paper insulation is different. LMA have been found to be more active in the degradation of paper insulation. LMA are mainly generated from the chemical hydrolytic processes in the paper and due to their polar and hydrophilic nature they tend to accumulate in the paper insulation [6,7]. Additionally, because the molecules are small they will also partition into the transformer liquid. Other factors that affect partitioning are: partial concentrations, polarity and temperature. LMA that are assumed to originate from the paper insulation ageing have a molar mass that ranges from 46 to $116 \mathrm{~g} \cdot \mathrm{mol}^{-1}$. HMA have much larger molar masses that are typically greater than 240 $\mathrm{g} \cdot \mathrm{mol}^{-1}[6]$. HMA have been found to be generated mainly from chemical oxidation processes relating to the transformer liquid and due to their non-polarity and large molecular size they tend to stay in the transformer liquid [8]. Therefore, they have a negligible effect on paper degradation. However, as explained in [6], the current methods of measuring acidity in transformer liquid is in its infancy, and is limited as it can only measure total acid number rather than specifically the more detrimental LMA. In order to investigate LMA in the ageing process of paper insulation they need to be accurately and reliably separated from the other acids in transformer liquid. There is no standard measurement method for the extraction process of LMA. Commonly seen methods involve using water to extract LMA due to their polar hydrophilicity and solubility in water $[6,8]$. Percentage extracted of LMA from transformer liquid could depend on different parameters of the extraction process. In this paper, the effects of stirring speed, stirring duration and acidity concentration on the extraction of 
LMA from transformer liquid using water will be investigated for two types of transformer liquids including a mineral oil and a synthetic ester.

\section{EXPERIMENTAL DESCRIPTION}

\section{A Test Objects}

In the experiment two types of transformer liquids were investigated: Nytro Gemini X (inhibited mineral oil) and MIDEL 7131 (synthetic ester). The transformer liquids were filtered using a nylon membrane of pore size $0.2 \mu \mathrm{m}$ and then degassed under vacuum at $85^{\circ} \mathrm{C}$ for 24 hours for the mineral oil and 72 hours for the ester. Formic acid of $>98 \%$ purity from Sigma Aldrich was used as a representative of the carboxylic acids belonging to LMA.

\section{B Determination of Formic Acid Concentration and Acidity Number}

Formic acids of masses ranging from 0.02 to $1 \mathrm{~g}$ were injected using a $500 \mu \mathrm{l} \mathrm{SGE}$ gas tight syringe (Sigma Aldrich) into $200 \mathrm{ml}, 500 \mathrm{ml}$ and $1000 \mathrm{ml}$ of transformer liquids and the acidity was measured using potentiometric dynamic endpoint titrations according to IEC 62021-1 and IEC 620213 , for mineral oils and synthetic esters respectively. A Metrohm 848 Titrino Plus with a Solvotrode easyClean glass electrode was used for the titration. The results are plotted in Fig. 1.

From Fig. 1 it can be seen that there is an approximate linear relationship between the acid added and the measured acidity for all investigated liquids. The figure shows how much acid needs to be added to get a particular acidity, which was used to control initial acidity concentration of the transformer liquids.

\section{Sample Preparation}

Two $500 \mathrm{ml}$ bottles with each type of transformer liquid were placed at room temperature and then injected with the appropriate mass of formic acid using the $500 \mu \mathrm{l}$ gas tight syringe according to Fig. 1. Acidity of approximately $0.1,0.3$ and $0.5 \mathrm{mg} \mathrm{KOH} / \mathrm{g}$ Oil, were prepared for each type of transformer liquid. The samples were then left to mix on a magnetic stirrer overnight (12 hours). The final acidity values obtained for each transformer liquid type are shown in Table 1.

Table 1 Controlled Initial Acidity Concentrations of Transformer Liquids

\begin{tabular}{|l|c|c|c|c|}
\hline \multicolumn{1}{|c|}{$\begin{array}{c}\text { Liquid } \\
\text { Type }\end{array}$} & $\begin{array}{c}\text { Acidity in New } \\
\text { Liquid (mg } \\
\text { KOH/g Oil) }\end{array}$ & \multicolumn{3}{|c|}{\begin{tabular}{c}
\multicolumn{3}{|c|}{ Controlled Acidity (mg KOH/g } \\
Oil)
\end{tabular}} \\
\hline Gemini X & $<0.01$ & 0.10 & 0.34 & 0.51 \\
\hline $\begin{array}{l}\text { MIDEL } \\
7131\end{array}$ & $<0.03$ & 0.11 & 0.31 & 0.50 \\
\hline
\end{tabular}

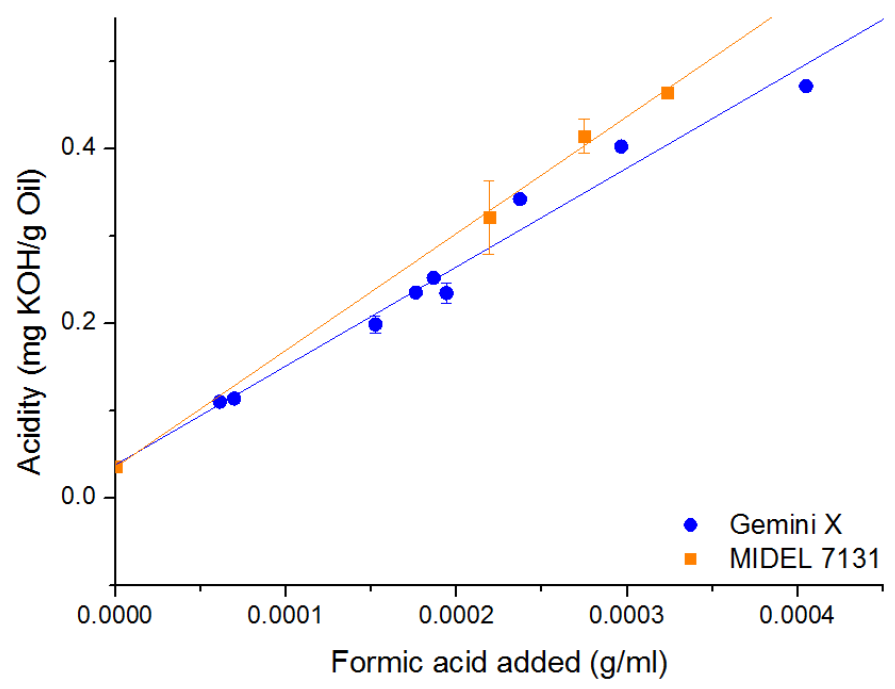

Fig. 1 - Concentration of added formic acid plotted against averaged acidity.

\section{Measurement of LMA in Transformer Liquid Samples}

LMA in transformer liquid was measured through the procedure shown in Fig. 2 and the parameters shown in the reference method of Table $2.25 \mathrm{ml}$ of analytical grade water was added into $25 \mathrm{ml}$ of transformer liquid. They were mixed on a magnetic stirrer for three hours and then left to separate for three hours into two distinctive layers. The two phases were then separated and the acidity was measured.

Effects of the stirring speed, stirring duration and the separation time on the LMA extraction process from the two transformer liquids were investigated individually while maintaining other parameters as in the reference method.

Table 2 - Parameters for the Acidity Separation Process

\begin{tabular}{|l|c|c|}
\hline \multicolumn{1}{|c|}{ Controlled Parameters } & Reference method & Variations \\
\hline Transformer liquid (ml) & 25 & - \\
\hline Water $(\mathrm{ml})$ & 25 & - \\
\hline Stirring Speed (rpm) & 650 & 300,650 and 1000 \\
\hline $\begin{array}{l}\text { Stirring Duration } \\
\text { (hours) }\end{array}$ & 3 & $1,3,5,7$ and 12 \\
\hline Separation Time (hours) & 3 & $0.25,0.5,1$ and 3 \\
\hline Temperature $\left({ }^{\circ} \mathrm{C}\right)$ & 20 & - \\
\hline
\end{tabular}

Step 1

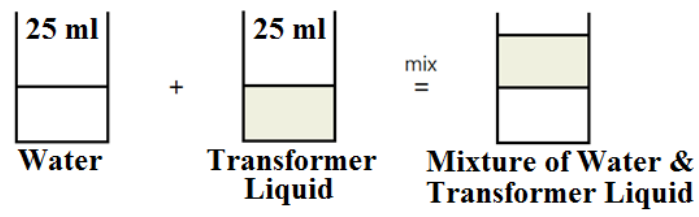

Step 2

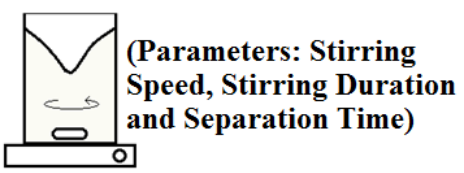

Stirring the Mixture

Step 3

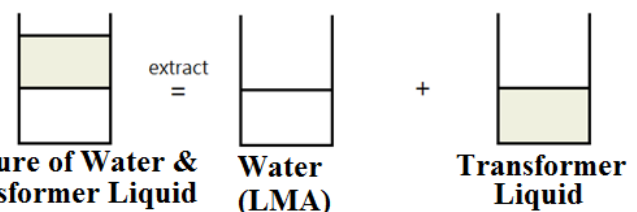

Fig. 2 - Water extraction technique to separate LMA from transformer liquids 


\section{RESULTS \& DISCUSSION}

\section{A Effect of Stirring Speed on LMA Percentage Extracted}

Fig. 3 shows a plot of percentage extracted against stirring speed for an initial acidity of $0.5 \mathrm{mg} \mathrm{KOH} / \mathrm{g}$ Oil in two transformer liquids. Percentage extracted is calculated by (1).

$$
\eta=\left[\frac{A_{2}}{A_{1}}\right] \times 100 \%
$$

Where $\eta$ is the percentage extracted (\%), $A_{1}$ is the initial acidity controlled in the transformer liquid and $A_{2}$ is the acidity of the extracted LMA in the water.

From Fig. 3, an optimum stirring speed of $650 \mathrm{rpm}$ was observed in terms of percentage extracted for Gemini X. A decrease in the percentage extracted was seen at both 300 and $1000 \mathrm{rpm}$. This could have occurred due to a slower rate of diffusion at lower stirring speeds and evaporation of formic acid at higher stirring speeds as a result of its volatility. For MIDEL 7131, there is a negligible change in the percentage extracted of LMA as the stirring speed increases from 300 to $1000 \mathrm{rpm}$. This phenomenon might be a result of MIDEL 7131 being a more polar molecule and mixing well with the water during the 3-hour stirring period. Experiments conducted using transformer liquid samples with an acidity of 0.1 and $0.3 \mathrm{mg} \mathrm{KOH} / \mathrm{g}$ Oil also indicated a similar optimum stirring speed.

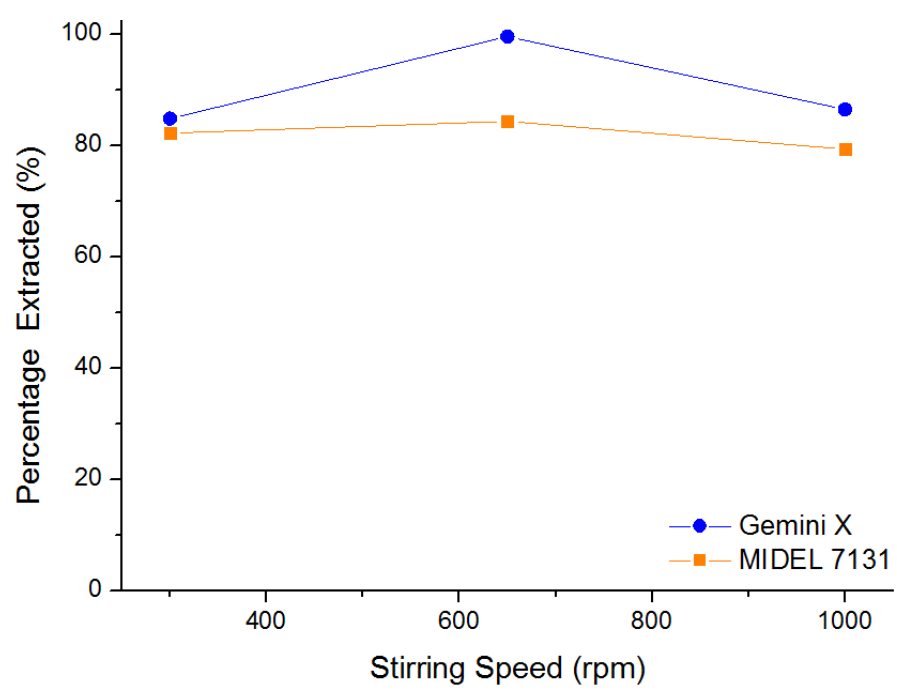

Fig. 3 - Percentage extracted against the stirring speed for Gemini $\mathrm{X}$ and MIDEL 7131 with an initial acidity of $0.5 \mathrm{mg} \mathrm{KOH} / \mathrm{g}$ Oil

\section{B Effect of Stirring Duration on LMA Extraction}

Fig. 4 shows the effect of stirring duration on the LMA extraction process. Experiment was conducted at $650 \mathrm{rpm}$ with an initial acidity of $0.5 \mathrm{mg} \mathrm{KOH} / \mathrm{g}$ Oil. The stirring duration of the samples was varied from 1 to 12 hours. The results show that for the mineral oil the extraction process is completed within the first hour, whereas for the synthetic ester this takes approximately upto three hours. The short period of time for extraction in the mineral oil is most likely due to its non-polar nature. The polar LMA molecules are more likely to diffuse into water rather than staying in oil. For MIDEL 7131 the attraction between LMA and ester can be stronger due to their polar nature, which is probably why it takes longer for LMA to be extracted into water from the synthetic ester. In addition, a residual amount of LMA was found in MIDEL 7131 even after 12 hours of stirring. This means that there will be a small amount of LMA than cannot be separated using water, which is trapped by the polar synthetic ester molecules via hydrogen bonding.

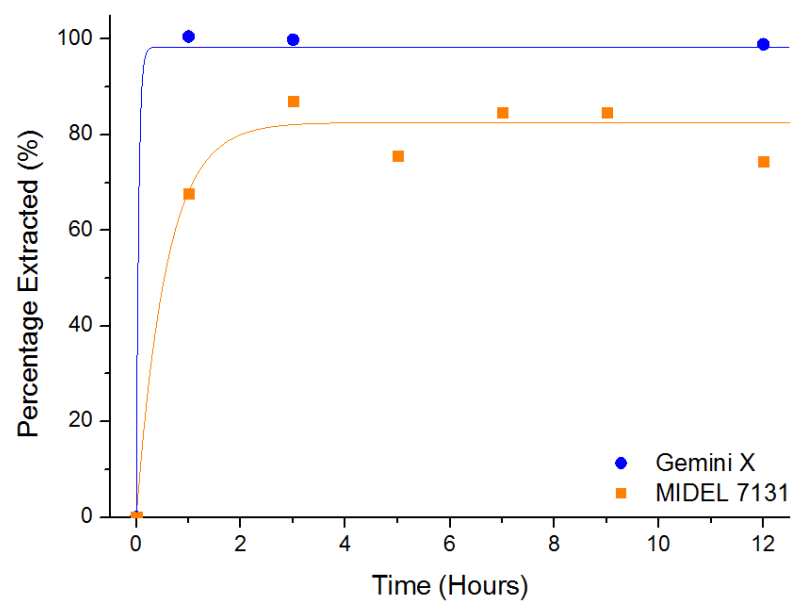

Fig. 4 - Acidity against time for Gemini $X$ and MIDEL 7131 stirred at 650 rpm with an initial acidity of $0.5 \mathrm{mg} \mathrm{KOH} / \mathrm{g}$ Oil

\section{Effect of Separation Time on LMA Extraction}

Even though the 3 hours of stirring together with 3 hours of separation time is sufficient, laboratories are interested in faster measurement procedures. Hence, the effect of separation time was investigated to determine the possibility of shortening the measurement duration. Transformer liquid samples prepared with $0.5 \mathrm{mg} \mathrm{KOH} / \mathrm{g}$ oil acidity were stirred at $650 \mathrm{rpm}$ for 3 hours and left to separate for different durations from 0.25 to 3 hours. Fig. 5 shows the acidity in water at different separation times. It can be seen that the acidity is constant and does not change as separation time changes from 0.25 to 3 hours for the two types of transformer liquids. This suggests that LMA has diffused into the water during the stirring period the separation time could be reduced to 0.25 hour (15 minutes) if desired.

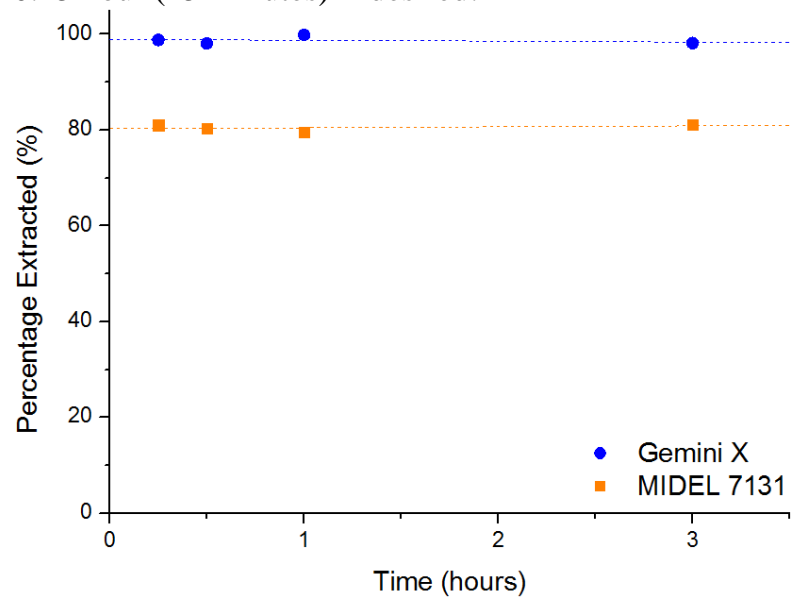

Fig. 5 - Acidity of water against separation time for Gemini X and MIDEL 7131 stirred at $650 \mathrm{rpm}$ with an initial acidity of $0.5 \mathrm{mg} \mathrm{KOH} / \mathrm{g}$ Oil 


\section{Effect of Initial Concentration on Extraction of LMA}

Fig. 6 shows the amount of extracted acids in water against the injected acidity in transformer liquid measured at three different initial acidity levels, which used the reference method in Table 2. For the investigated acidity range, the results show that close to $90 \%$ or more of LMA can be extracted from the mineral oil.

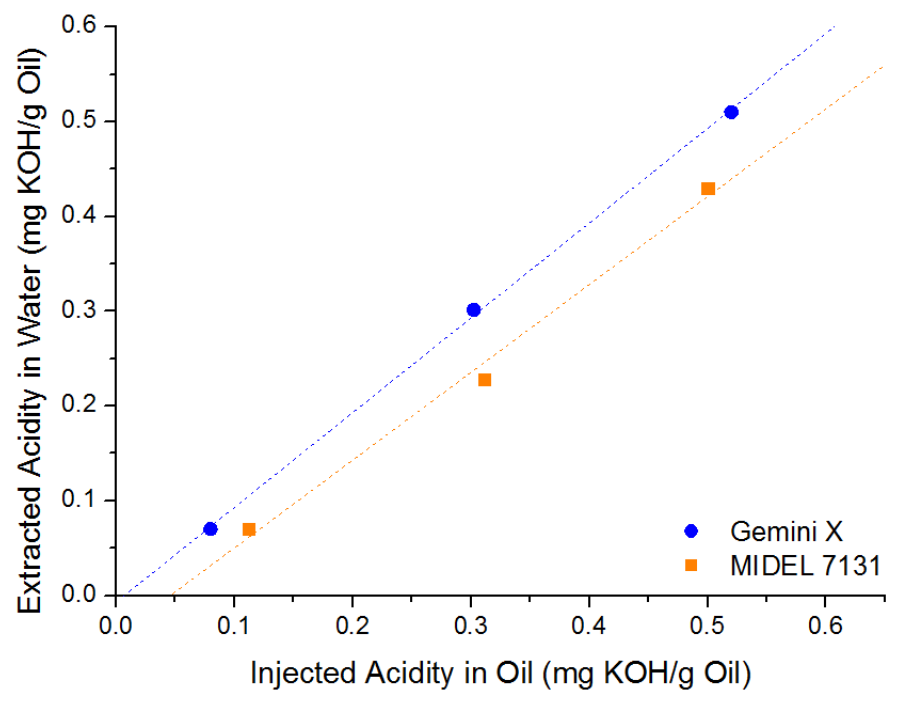

Fig. 6 - Deviation of extracted Acidity for Gemini X and MIDEL 7131

However, for synthetic ester, extraction was lower than the mineral oil. This was a result of the residual LMA, which is higher in ester liquids due to their increased polarity. From the experiments the residual amount for synthetic ester was seen to be approximately $0.042 \mathrm{mg} \mathrm{KOH} / \mathrm{g}$ Oil, and as can be seen from the line fitting intercept on the $\mathrm{x}$ axis of Fig. 6. The residual amount of Gemini $\mathrm{X}$ is much lower and close to $0.007 \mathrm{mg} \mathrm{KOH} / \mathrm{g}$ Oil.

For example, Fig. 6 could be used as a calibration curve to calculate the LMA (Formic acid) in the actual samples of transformer liquids within this study from their LMA measurements in water. Two equations are obtained; one for Gemini X, and one for MIDEL 7131, (2) and (3) respectively.

$$
\begin{gathered}
A_{G i}=0.007+A_{G W} \\
A_{M i}=0.042+0.927 A_{M W}
\end{gathered}
$$

Where $A_{G W}$ is the acidity, in $\mathrm{mg} \mathrm{KOH} / \mathrm{g}$ Oil, of LMA extracted from Gemini $\mathrm{X} ; A_{M W}$ is the acidity, in $\mathrm{mg} \mathrm{KOH} / \mathrm{g}$ Oil, of LMA extracted from MIDEL 7131; $A_{G i}$ is the initial acidity in Gemini X. $A_{M i}$ is the initial acidity in MIDEL 7131.

The anticipated outcome is that a method has been developed whereby LMA (which are more polar and hence more soluble in water and paper) are preferentially removed from oil by water whereas HMA are less polar and tend to stay in the transformer liquid. The types of acid that are more soluble to water (and paper) are therefore more likely to be detrimental to paper and hence transformer lifetime. Therefore this method can provide greater understanding of acidity number.

\section{CONCLUSION}

A water extraction technique for LMA in a mineral oil and a synthetic ester was investigated. The effects of the following parameters: stirring speed, stirring duration, liquid type, acidity concentration, and separation period were studied. A reference method was optimised at the room temperature whereby samples are stirred at $650 \mathrm{rpm}$; stirred for a duration of 1 hour for mineral oils and 3 hours for synthetic esters; and then left to separate for 30 minutes.

It was also found that the ultimate extraction of acid in the synthetic ester will always be less than that in the mineral oil at the same initial LMA concentration due to its polar chemical nature. A residual of acids was also noticed during the extraction of LMA from the synthetic ester. It was noticed from the experiments to be approximately $0.042 \mathrm{mg} \mathrm{KOH} / \mathrm{g}$ Oil. However, the study needs to extend to other types of LMA.

\section{ACKNOWLEDGMENT}

The authors would like to acknowledge the contributions on experiments and discussions from J. Hill, M. K. Leong, Z. Liu, L. Zou and R. Chen to this study. Z. W. Yan acknowledges financial support from EPSRC (EP/L016141/1) through the Power Networks Centre for Doctoral Training.

\section{REFERENCES}

S. J. Tee, Q. Liu, Z. D. Wang, G. Wilson, P. Jarman, R. Hooton, et al., "An early degradation phenomenon identified through transformer oil database analysis," IEEE Transactions on Dielectrics and Electrical Insulation, vol. 23, pp. 1435-1443, 2016. "IEC 60076-7 Power transformers - Part 7: loading guide for mineral-oil-immersed power transformers (Edition 2.0)," International Electrotechnical Commission (IEC), 2018.

S. Y. Matharage, Q. Liu, and Z. D. Wang, "Aging assessment of kraft paper insulation through methanol in oil measurement," IEEE Transactions on Dielectrics and Electrical Insulation, vol. 23, pp. 1589-1596, 2016.

L. E. Lundgaard, W. Hansen, D. Linhjell, and T. J. Painter, "Aging of oil-impregnated paper in power transformers," IEEE Transactions on Power Delivery, vol. 19, pp. 230-239, 2004.

"IEC 60422:2013 Mineral insulating oils in electrical equipmentsupervision and maintenance guidance (Edition 4.0)," International Electrotechnical Commission (IEC), 2013.

L. E. Lundgaard, W. Hansen, and S. Ingebrigtsen, "Ageing of Mineral Oil Impregnated Cellulose by Acid Catalysis," IEEE Transactions on Dielectrics and Electrical Insulation, vol. 15, pp. 540-546, 2008.

S. Ingebrigtsen, M. Dahlund, W. Hansen, D. Linhjell, and L. E. Lundgaard, "Solubility of carboxylic acids in paper (Kraft)-oil insulation systems," in Electrical Insulation and Dielectric Phenomena, 2004. CEIDP '04. 2004 Annual Report Conference on, 2004, pp. 253-257.

N. Azis, Q. Liu, and Z. D. Wang, "Ageing assessment of transformer paper insulation through post mortem analysis," IEEE Transactions on Dielectrics and Electrical Insulation, vol. 21, pp. 845-853, 2014.

"IEC 62021-1: 2003 Insulating liquids Determination of acidityPart 1: Automatic potentiometric titration," International Electrotechnical Commission (IEC), 2003.

S. Tenbohlen and M. Koch, "Aging Performance and Moisture Solubility of Vegetable Oils for Power Transformers," IEEE Transactions on Power Delivery, vol. 25, pp. 825-830, 2010. 